\title{
Models of Integration of Specialized Palliative Care with Oncology
}

Jean Mathews, $M D^{1,2}$

Breffni Hannon, MB BCh MMedS $\mathrm{Ci}^{1,2,3}$ Camilla Zimmermann, MD PhD $D^{1,2,3, *}$ 。

\section{Address}

${ }^{1}$ Department of Supportive Care, Princess Margaret Cancer Centre, University Health Network, 610 University Ave., 16-712, Toronto, Ontario, M5G 2M9, Canada

${ }^{2}$ Divisions of Palliative Medicine and Medical Oncology, University of Toronto, Toronto, Canada

*,3 Department of Medicine, University of Toronto, Toronto, Canada

Email: camilla.zimmermann@uhn.on.ca

Published online: 8 April 2021

(C) The Author(s), under exclusive licence to Springer Science+Business Media, LLC, part of Springer Nature 2021

This article is part of the Topical Collection on Palliative and Supportive Care

Keywords Palliative care $\cdot$ Oncology $\cdot$ Neoplasms $\cdot$ Quality of life $\cdot$ Telemedicine $\cdot$ Models of care $\cdot$ Integration . Integrated healthcare systems

\section{Opinion statement}

Evidence from randomized controlled trials and meta-analyses has shown that early integration of specialized palliative care improves symptoms and quality of life for patients with advanced cancer. There are various models of early integration, which may be classified based on setting of care and method of palliative care referral. Most successful randomized controlled trials of early palliative care have used a model of specialized teams providing in-person palliative care in free-standing or embedded outpatient clinics. During the COVID-19 pandemic, telehealth has become a prominent model for palliative care delivery. This model of care has been well received by patients and palliative care providers, although evidence to date is limited. Despite evidence from trials that routine early integration of palliative care into oncology care improves patient outcomes, referral to palliative care still occurs mostly according to the judgment of individual oncologists. This hinders equitable access to palliative care and to its known benefits for patients and their caregivers. Automated referral based on triggering criteria is being actively explored as an alternative. In particular, routine technology-assisted symptom screening, combined with targeted needs-based automatic referral to outpatient palliative care, may improve integration and ultimately increase quality of life. 


\section{Introduction}

Palliative care is aimed at improving the quality of life (QoL) of patients and their families facing lifethreatening illnesses including cancer, by timely identification, assessment, and treatment of physical, psychosocial, or spiritual issues [1]. In the last decade, randomized controlled trials (RCTs) have consistently demonstrated the benefit of early specialized palliative care to improve symptoms and quality of life for patients with advanced cancer $[2-6 \bullet \bullet]$ as well as satisfaction with care for their caregivers $[7 \bullet \bullet]$. As a result, the American Society of Clinical Oncology and the European Society for Medical Oncology have recommended early integration of palliative care services alongside oncology $[8 \bullet \bullet, 9]$.

Major indicators for integration of palliative care into oncology care at cancer centers include the presence of a specialized interdisciplinary palliative care team, an outpatient palliative care clinic, routine symptom screening in outpatient oncology clinics, and early referral to specialized palliative care [10]. However, there are various models for the delivery of early specialized palliative care that may utilize some or more of these elements. Further, telehealth has recently become an increasingly prevalent method of providing compassionate care while maintaining physical distancing during the COVID-19 pandemic [11].

In this paper, we review current evidence for early integration of specialized palliative care into cancer care and describe the effect that this evidence has had on clinical practice. We also outline key elements of early palliative care and describe different models for its provision based on setting and methods of referral.

\section{Primary and specialized palliative care}

Palliative care can be described as either specialized or generalist, based on the provider $[6 \bullet \bullet, 12]$. Specialized palliative care refers to care provided by a multidisciplinary team trained in palliative care at an advanced level [13]. At its core, this team has a specialized palliative care physician and nurse; additional disciplines include psychologists, social workers, spiritual care providers, and others $[10,14]$. Generalist palliative care includes basic symptom management and goals of care discussions that should be provided by family physicians, oncologists, and other healthcare providers [12]. Family physicians and advanced practice nurses play a vital role in palliative care provision but may lack specific knowledge and skills related to oncology [15]. For oncologists and specialized oncology nurses, limited time and lack of training are frequently cited as barriers to providing comprehensive palliative care $[13,16]$.

There is no single model of palliative care that is appropriate for all settings. Rather, the structure of palliative care provision will depend on national health policies, access to training and education of specialized palliative care providers, availability of resources, societal and health professional attitudes towards palliative care, and the setting where palliative care is provided [17]. Funding models may particularly influence the development and provision of palliative care in different national policy contexts [18]. However, a model that facilitates the expansion of generalist palliative care provision for all patients with advanced cancer, with specialized palliative care referral reserved for those with refractory symptoms and complex needs, may offer the best solution to ensuring timely access to palliative care services $[12,19]$. The strongest evidence for improved patient outcomes has come from integrating a specialized palliative care team alongside routine oncology care early in the disease course for patients with cancer [13, 20-24]. 


\section{Evidence for early integration of specialized palliative care}

In the last decade, there have been multiple RCTs demonstrating the benefits of early integration of specialized palliative care. Most of these took place in North America and Europe and assessed in-person care (Table 1), but a few have assessed early palliative care delivered by telehealth (Table 2).

\section{RCTs of in-person early palliative care in North American settings}

The first in-person RCT of early palliative care took place in the USA (Table 1). In 2010, Temel et al. reported an RCT of early palliative care versus standard oncologic care for patients with newly diagnosed metastatic non-small-cell lung cancer [3]. The palliative care intervention was provided by specialist palliative care physicians and advanced practice nurses and resulted in improved mood and QoL; longer survival was also reported. In 2014, Zimmermann et al. reported on a Canadian cluster-RCT of early palliative care (clinical prognosis of 6-24 months) versus routine oncology care for patients with lung, gastrointestinal, genitourinary, breast, and gynecological cancers [2]. The intervention was delivered by a specialist palliative care physician and nurse in a freestanding clinic and led to improved QoL, satisfaction with care, symptom control for patients, and satisfaction with care of both patients and caregivers [7••]. In 2017, Temel et al. reported on an RCT of early palliative care (within 2 months of diagnosis) for patients with advanced lung and non-colorectal

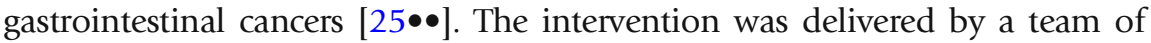
palliative care physicians and advanced practice nurses; it resulted in improved QoL, mood, coping with prognosis, and communication about end-of-life care preferences for patients, as well as less depression and anxiety for caregivers [34].

\section{RCTs of in-person early palliative care in European settings}

The largely positive findings of North American early palliative care RCTs have been replicated in Europe. In 2016, Maltoni et al. reported on an Italian multicenter RCT of systematic early versus on-demand palliative care for patients with metastatic or locally advanced inoperable pancreatic cancer; early was defined as within 2 months of diagnosis of advanced disease [26]. The intervention was delivered by a specialist physician and resulted in improved QoL at 3 months. In 2018, Vanbutsele et al. reported on an RCT of early systematic palliative care-defined as an estimated prognosis of less than 12 months and within 3 months of diagnosis-for patients with advanced solid tumor diagnoses $[4 \bullet \bullet]$. The intervention was delivered by palliative care nurses, with specialized palliative care physicians available on demand, and resulted in improved QoL compared to the controls receiving standard care that included psychosocial support.

Three other recent European studies did not show findings favoring the intervention group. In 2017, Groenvold et al. reported on a multicenter RCT of early palliative care for patients with metastatic cancer [27]. The intervention was delivered by a multidisciplinary team, with no significant effect on the primary outcome of QoL or survival at 2 months. Possible explanations 


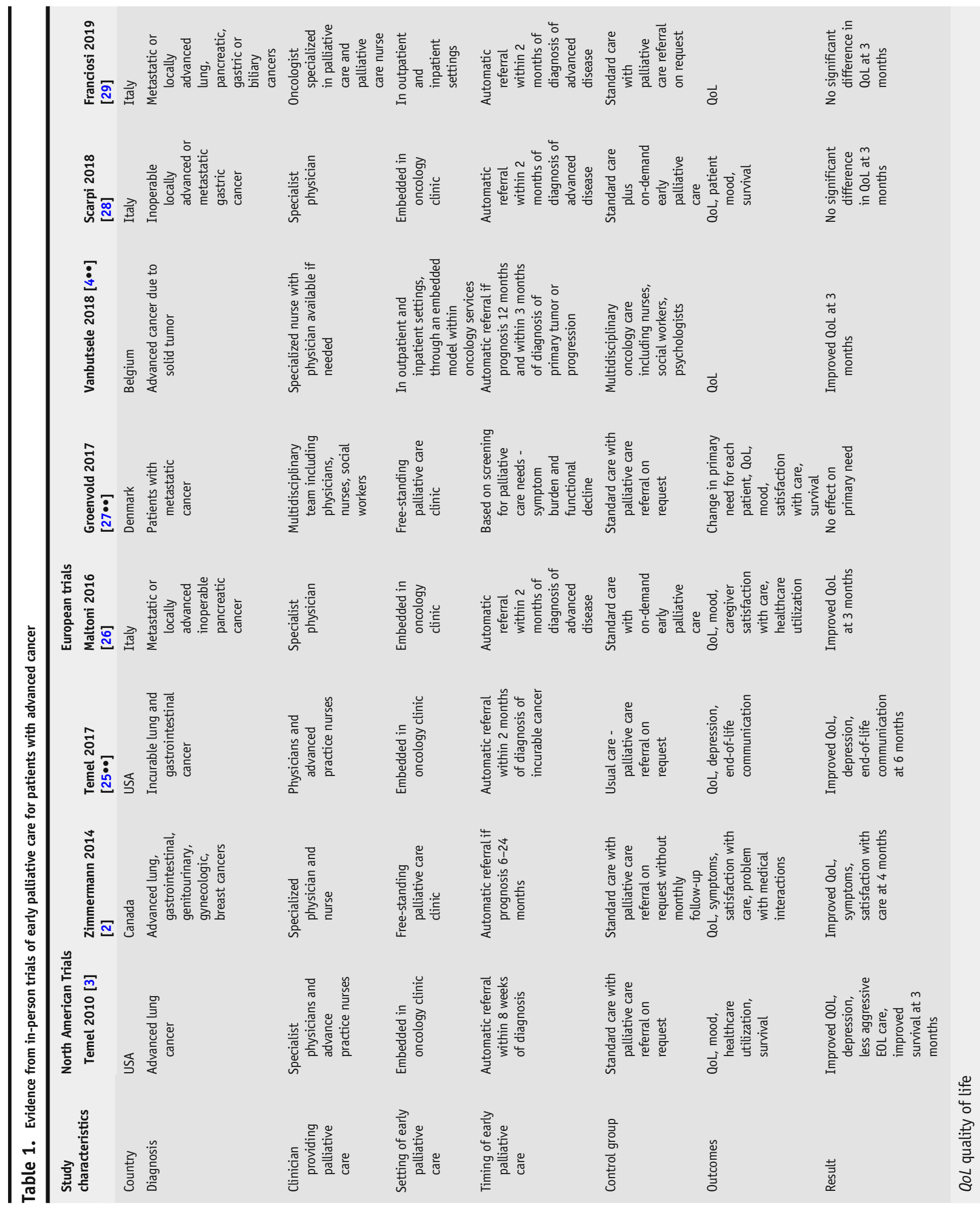


included the lack of training of the team in early delivery of palliative care and a relatively short outcome assessment period. In 2018, Scarpi et al. published a multicenter RCT of systematic referral (within 2 months of diagnosis) to a single palliative care physician versus on-demand palliative care for patients with advanced gastric cancer; there was no significant difference in QoL [28]. In 2019, Franciosi et al. reported on a multicenter RCT of patients with advanced cancer who received early palliative care delivered by a specialized physician and nurse, or standard oncology care [29]; the results demonstrated no significant difference in QoL. Contamination in the control arm and lack of pilot testing of intervention were among the limitations reported.

\section{RCTs of early palliative care via telehealth}

The World Health Organization defines telehealth as the "delivery of healthcare services, where patients and providers are separated by distance" [35]. There have been few RCTs of telehealth delivered by palliative care teams, with many consisting of psychosocial interventions, or conducted in early-stage cancer populations [36]. Systematic reviews of telehealth interventions in palliative care have identified heterogeneity in study designs, interventions, and outcomes measured and have emphasized the need for further high-quality trials in this area $[37,38]$.

Table 2 summarizes recent evidence from trials for telehealth-specialized palliative care interventions for patients with advanced cancer. In 2009, Bakitas et al. reported on an RCT of a nurse-led psychoeducational telehealth intervention for patients with newly diagnosed advanced cancer in a rural setting, which showed benefits from early palliative care on both QoL and mood [30]. In 2013, Kim et al. reported on an RCT testing the effectiveness of daily telemonitoring for pain in outpatients with advanced solid tumors [31]. The intervention was delivered over telephone by a nurse practitioner specialized in pain management and resulted in improvements in pain, anxiety, and QoL after 1 week. In 2015, Bakitas et al. reported on a US trial of early (within 2 months of diagnosis, clinical prognosis 6-24 months) versus delayed palliative care (3 months later) for patients with advanced cancer in a rural setting [32]. The intervention was a mixed model consisting of an in-person consult with a palliative care clinician, weekly telehealth nurse-led coaching for 6 weeks, and monthly follow-up calls. Although there was no difference in patient-reported outcomes, 1-year survival was better for the intervention group; a parallel caregiver intervention resulted in improved depression and decreased caregiver burden [39]. In 2017, Hoek et al. reported on an RCT of weekly telehealth specialist palliative care, compared to primary palliative care provided by general practitioners, for home-dwelling advanced cancer patients [33]. The intervention was provided by specialist nurses or physicians; the intervention arm reported increased symptom burden, which might have been due to higher awareness and reporting from the close attention to symptoms.

\section{Meta-analyses of early palliative care trials}

Six meta-analyses have synthesized results from the trials mentioned above and others of palliative care integrated later in the illness; all demonstrated improved outcomes. Kavalieratos et al. conducted a meta-analysis including 43 RCTs with 12,731 patients and 2479 caregivers to determine the association of 
Table 2. Evidence for telehealth-specialized early palliative care for patients with advanced cancer

\begin{tabular}{|c|c|c|c|c|}
\hline $\begin{array}{l}\text { Study } \\
\text { characteristics }\end{array}$ & Bakitas 2009 [30] & Kim 2013 [31] & Bakitas 2015 [32] & Hoek 2017 [33] \\
\hline Country & USA & South Korea & USA & The Netherlands \\
\hline Diagnosis & Advanced cancer & $\begin{array}{l}\text { Stage IV solid } \\
\text { tumor }\end{array}$ & Advanced cancer & Advanced cancer \\
\hline $\begin{array}{l}\text { Telehealth tools } \\
\text { used }\end{array}$ & Telephone & Telephone & Telephone & $\begin{array}{l}\text { Videoconferencing using } \\
\text { iPads }\end{array}$ \\
\hline $\begin{array}{l}\text { Nature of } \\
\text { intervention }\end{array}$ & $\begin{array}{l}\text { Structured } \\
\text { psychoeducational } \\
\text { and } \\
\text { problem-solving } \\
\text { sessions }\end{array}$ & $\begin{array}{l}\text { Standardized pain } \\
\text { education and } \\
\text { telemonitoring }\end{array}$ & $\begin{array}{l}\text { Initial in-person consult } \\
\text { followed by weekly } \\
\text { telephone coaching } \\
\text { sessions }\end{array}$ & $\begin{array}{l}\text { Weekly multidisciplinary } \\
\text { palliative care }\end{array}$ \\
\hline Control group & Usual oncology care & $\begin{array}{l}\text { Standardized pain } \\
\text { education using } \\
\text { video-aided } \\
\text { presentation }\end{array}$ & $\begin{array}{l}\text { Delayed palliative care } \\
\text { initiation after three } \\
\text { months }\end{array}$ & $\begin{array}{l}\text { Primary palliative care by } \\
\text { general practitioners } \\
\text { supported by specialist } \\
\text { as needed }\end{array}$ \\
\hline $\begin{array}{l}\text { Clinician } \\
\text { providing } \\
\text { palliative care }\end{array}$ & $\begin{array}{l}\text { Advanced practice } \\
\text { nurses with } \\
\text { palliative care } \\
\text { specialized } \\
\text { training }\end{array}$ & $\begin{array}{l}\text { Nurse practitioner } \\
\text { trained in pain } \\
\text { management }\end{array}$ & $\begin{array}{l}\text { Board-certified palliative } \\
\text { care clinician and } \\
\text { advanced practice } \\
\text { nurse }\end{array}$ & $\begin{array}{l}\text { Specialist palliative care } \\
\text { nurse or physician }\end{array}$ \\
\hline $\begin{array}{l}\text { Timing of early } \\
\text { palliative care }\end{array}$ & $\begin{array}{l}\text { Within 8-12 weeks of } \\
\text { new diagnosis }\end{array}$ & $\begin{array}{l}\text { Targeted: pain } \\
\text { score }>4 / 10\end{array}$ & $\begin{array}{l}\text { Within } 30-60 \text { days of } \\
\text { diagnosis (early } \\
\text { group) or } 3 \text { months } \\
\text { later (delayed group) }\end{array}$ & $\begin{array}{l}\text { At diagnosis of advanced } \\
\text { disease }\end{array}$ \\
\hline Outcomes & $\begin{array}{l}\text { QoL, symptom } \\
\text { intensity, mood }\end{array}$ & $\begin{array}{l}\text { Pain, mood, } \\
\text { distress, } Q \mathrm{oL}\end{array}$ & $\begin{array}{l}\text { QoL, symptom impact, } \\
\text { mood, 1-year survival }\end{array}$ & Symptom burden, mood \\
\hline Results & $\begin{array}{l}\text { Improved QoL and } \\
\text { mood }\end{array}$ & $\begin{array}{l}\text { Improved pain at } 1 \\
\text { week }\end{array}$ & $\begin{array}{l}\text { Improved 1-year survival; } \\
\text { no difference in QoL, } \\
\text { symptoms, mood }\end{array}$ & $\begin{array}{l}\text { Higher symptom burden } \\
\text { at } 3 \text { months in } \\
\text { intervention arm }\end{array}$ \\
\hline
\end{tabular}

palliative care with outcomes for adults with life-limiting illnesses and their caregivers [40]. Palliative care interventions were associated with significant improvements in patient QoL and symptom burden, but not increased survival; findings for caregivers were inconsistent. Gaertner et al. assessed the effect of multidisciplinary specialist palliative care on QoL for patients with any advanced illness, assessing ten RCTs with 2454 patients, of whom $76 \%$ had cancer [41•]. Results favored the intervention, with a larger effect for patients with cancer and for those receiving early specialist palliative care. Haun et al. compared early palliative care to usual care for patients with advanced cancer, including seven RCTs that recruited 1614 patients [5]. Results showed beneficial effects for QoL and symptom intensity, albeit with small effect sizes. Kassianos et al. evaluated the impact of specialized palliative care on cancer patients' QoL [42] in 11 studies including five RCTs and 2939 patients. QoL was improved, especially for symptoms and physical and psychological functioning. Fulton 
et al. evaluated the effects of integrated outpatient palliative care in 10 RCTs for patients with advanced cancer and reported improved QoL, symptom burden, and survival [43]. Hoerger et al. assessed the impact of interdisciplinary outpatient specialty palliative care in adults with advanced cancer [22]. Reporting on nine RCTs, there were significant benefits in 1-year survival and QoL.

\section{Change in clinical practice following RCTs of early palliative care}

Recent studies comparing practice patterns in the USA and Canada suggest that the evidence from RCTs of early palliative care has influenced referral patterns and policies. A study conducted at the Princess Margaret Cancer Centre in Toronto, Canada, showed that between 2006 and 2015, late referrals (within 6 months of death) decreased from 69 to $45 \%$, and the median time from referral to death doubled from 3.5 to 7.0 months [44•]. As well, a national survey of palliative care services in US cancer centers reported that outpatient services increased significantly from 59 in 2009 to $95 \%$ in 2018 [45], and the median time from outpatient palliative care referral to death doubled during this 9-year interval. Together, these results suggest that research findings and clinical practice guidelines have increased the utilization of outpatient palliative care as the prime setting for early integration into oncology [46] and that oncologists are referring substantially earlier to these clinics in North America.

Data regarding potential changes in referral practices from countries outside North America are lacking. A recent systematic review that examined the duration of palliative care received by patients before death in 169 studies from 23 countries reported that the median duration from initiation of palliative care to death was 18.9 days [47]. However, this review included studies conducted before evidence was published from RCTs supporting early palliative care, and the majority of studies were conducted on palliative care units, inpatient services, and in the home setting, rather than in ambulatory palliative care settings. Moreover, length of stay in an acute palliative care unit was assumed to be the time from referral to death, whereas patients often do not have their first contact with a palliative care team in the palliative care unit, and many are discharged home after acute pain and symptom management (approximately $50 \%$ on our service). Further research is required to assess changes in referral patterns over time in international settings, as well as best practices internationally for early palliative care integration.

\section{Key elements of early specialized palliative care}

Qualitative research with patients and caregivers who have received early palliative care has revealed several key elements, which can be divided into principles and domains of care (Fig. 1) $[48 \bullet \bullet, 49,50 \bullet \bullet]$. Principles of care refer to the manner in which care is delivered; patients and caregivers have described early specialized care as being flexible in its approach and timing, attentive to patient and caregiver needs, led by the patient rather than the clinician, and centered on the family unit of care $[48 \bullet \bullet, 49]$. Domains of care refer to four key areas through which early palliative care benefits patients and caregivers: coping and support that encompasses the patient and their family; prompt personalized symptom control; assistance with medical decision-making, especially during transitions in care or critical clinical time points; and planning for the 


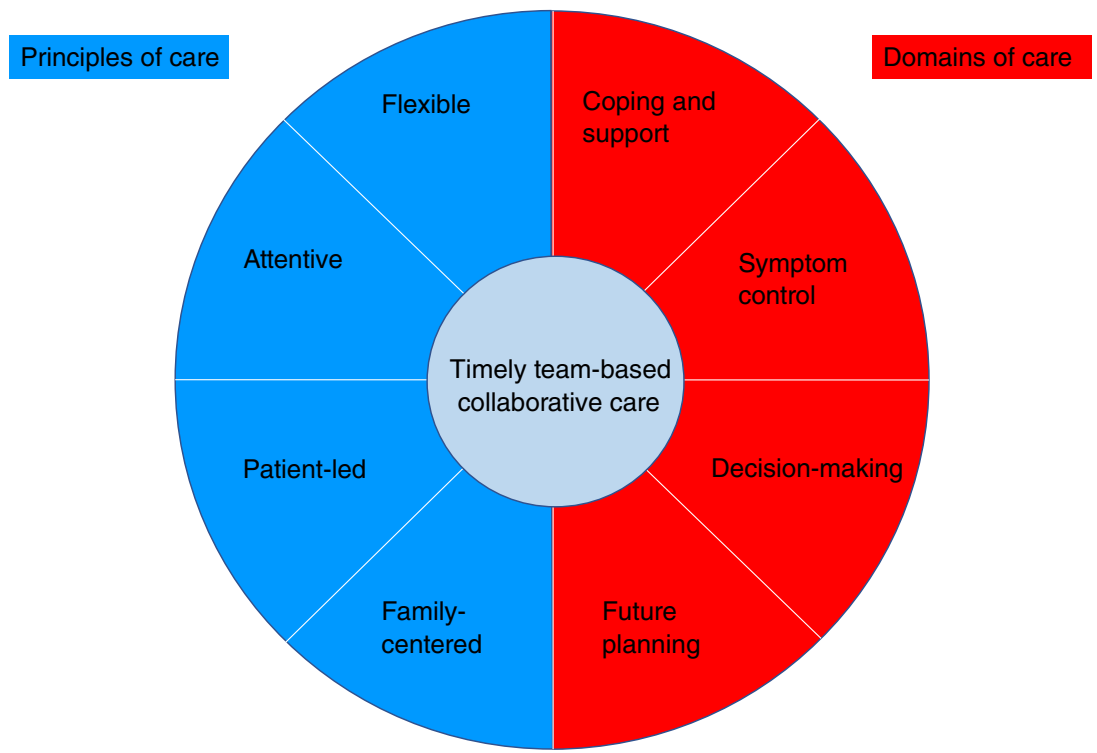

Fig. 1. Key elements of early palliative care. The key elements of early palliative care can be divided into two broad areas: principles and domains of care. We identify four key principles on how care should be provided (care that is flexible, attentive, patient-led, and family-centered) and four key domains (support and coping, managing symptoms, assisting with medical decision-making, and planning for the future).

future $[48 \bullet \bullet, 50 \bullet \bullet$. Initial outpatient palliative care clinic visits tend to focus on coping, support, and symptom management; the longitudinal trust and rapport developed over time with the palliative care team can be leveraged to explore

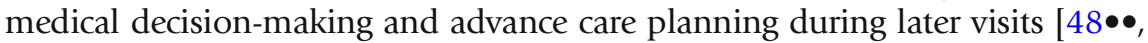
$50 \bullet \bullet, 51]$. These basic elements of care may be used to guide both primary and specialized palliative care both in clinical practice and for future trials.

\section{Settings for specialized palliative care}

Early palliative care is best delivered in outpatient clinics or in the patient's home $[8 \bullet \bullet$. Four models of integration have been described, based on the location of care: the embedded clinic, the free-standing palliative care clinic, home-based palliative care, and palliative care by telehealth.

\section{Embedded palliative care clinic}

In this model, the palliative care clinic operates out of a shared space within the oncology clinic. Several studies have described positive outcomes related to embedded clinics, including less aggressive end-of-life care and earlier hospice utilization [52] and improved documentation of advance care plans [53]. The main advantage of an embedded model is geographic proximity to the oncology team, which may destigmatize referrals and facilitate integration [13]. Sharing resources between oncology and palliative care services is also costeffective and may encourage collaborative education and research. Disadvantages include constrained space and time for palliative care in the shared clinic, limiting growth or expansion [23], and logistics of embedding palliative care 
providers in numerous tumor site-specific oncology clinics in large cancer centers. A retrospective cohort study in patients with advanced lung cancer found that despite earlier access, symptom control or QoL did not improve for patients in an embedded clinic, compared to a free-standing palliative care clinic [54].

\section{Free-standing palliative care clinic}

Outpatient palliative care clinics are recommended as the optimal model for early integration alongside oncology $[8 \bullet \bullet, 22,24,48 \bullet \bullet]$. In this model, the multidisciplinary palliative care team operates out of an independent clinic space within the hospital $[14,55]$. These clinics are most commonly located in tertiary cancer centers where they offer scheduled and urgent, same-day appointments; in-person or virtual follow-up; a telephone triage line for urgent symptoms; and after-hours support [14]. Much of the evidence supporting early palliative care integration has come from RCTs conducted in free-standing clinics $[2,3,25 \bullet \bullet, 26]$, which offer greater scope to expand clinical, educational, and research activities [13]. As for any hospital service, these clinics require investment in terms of space, staffing, equipment, and other resources.

The Princess Margaret Cancer Centre in Toronto, Canada, has a free-standing 12-room palliative care clinic that operates 5 days a week, staffed by a team of specialized physicians and nurses; other allied healthcare workers are available as needed, including spiritual counselors, social workers, physiotherapists, occupational therapists, and wound care nurses [14]. The clinic offers scheduled appointments, as well as urgent same-day consultations for patients with severe, uncontrolled symptoms. A nurse-led telephone triage line is available for patients at home who develop urgent symptoms, with after-hours physician telephone support ensuring 24/7 coverage. Patients who can no longer attend clinic visits due to disease progression and functional decline are referred to home visiting palliative care doctors or to hospice care, guided by the patients' wishes.

Home-based palliative care is traditionally provided by primary care physicians (family physicians or GPs), nurses, or hospice/palliative care teams when patients are no longer receiving systemic cancer treatments and/or when their performance status limits the ability to attend hospital appointments. Attempts to integrate home-based palliative care by primary care providers earlier for patients with advanced cancer have identified barriers, including poor communication and coordination between oncologists and community-based providers and knowledge gaps around cancer therapies and illness trajectories [56]. Primary care physicians may also have limited time for home visits and may deprioritize palliative care, particularly early in the disease course [57]. Family physicians working in teams, rather than individually, and those with greater availability of community and psychosocial supports, have been identified as being better resourced to provide early palliative care [58•]. Trials of early integrated home-based palliative care for patients with advanced cancer are at an early stage, and further research is needed [59].

\section{Telehealth palliative care clinic}

In the telehealth model of palliative care, the patient and family are in their home, and members of the palliative care team communicate with them using 
telephone or videoconferencing tools. This model of care has risen in prominence and utility during the COVID-19 pandemic, including at our center [60•]. Before March 2020, approximately 330 patients were seen monthly at the Princess Margaret Cancer Centre's palliative care clinic-all in person. By the summer of $2020,>400$ patients were seen monthly, and $>90 \%$ were telehealth visits.

Telehealth palliative care is convenient for both patients and caregivers, providing them with seamless care and promoting their independence [61 $\bullet$; it is also a promising model for patients living in rural and geographically remote locations where access to in-person care is limited [62-64]. In lowand middle-income countries, where infrastructure and financial constraints are barriers to accessing both cancer treatments and palliative care, telehealth may facilitate access in a cost-effective manner $[65,66]$. Advanced cancer is associated with increased financial distress for patients and their family caregivers $[67$, $68]$, and telehealth may provide a means of supporting early access to palliative care without adding to this burden. In particular, indirect costs may be minimized, including those associated with travel to the hospital, time away from work, or childcare costs for patients and caregivers. Further research in this regard is warranted.

The telehealth model also has limitations, such as the inability to conduct a physical examination to assess for ascites or pleural effusions, or for managing oncologic emergencies such as spinal cord compression. Other disadvantages include diminished detection of non-verbal cues, as well as technical issues related to virtual platforms [69]. Despite these limitations, this model of care has been received positively by both patients and palliative care providers [70]. Research on several telehealth palliative care interventions is ongoing [71, 72], and the next decade will undoubtedly bring a wealth of evidence in this regard.

\section{Methods of referral to specialized palliative care services}

Traditionally, palliative care referral is initiated based on the judgment of the patient's oncologist. However, there are other methods of referral, which allow varying levels of judgment versus automatic triggering. These are described below.

\section{Oncologist-initiated referral based on clinical judgment alone}

In this model, palliative care referrals are initiated by oncologists, without attending to specific referral criteria. However, despite ample evidence favoring early referral, oncologists may have varying referral practices, leading to inconsistent integration [73]. Although early referrals tend to be for symptom management, referral for some patients with severe symptoms may not occur, resulting in suboptimal care [74]. Barriers to oncologist-based referrals include unrealistic patient and family expectations or stigma around the term palliative care; fear of eroding the oncologist-patient relationship or removing hope; and lack of confidence around initiating discussions with patients about referral to palliative care [75]. Oncologists may believe that palliative care is incompatible with active anticancer therapy or that they can provide comprehensive palliative care to their own patients; they may also lack knowledge about available palliative care services [76]. Routine rotations in palliative care for oncology trainees have been shown to increase referrals [73]; continuing medical 
education in palliative care for attending oncologists is important to facilitate ongoing integration $[6 \bullet \bullet, 10]$.

\section{Oncologist-initiated referral guided by referral criteria}

Referral criteria for outpatient palliative care may be based on physical symptoms, the cancer trajectory, prognosis, performance status, psychosocial distress, end-of-life care planning, or a combination of the above [77]. Eleven major criteria for referral were identified in a recent Delphi study: severe physical symptoms, severe emotional symptoms, request for hastened death, spiritual or existential crisis, assistance with decision-making or planning, patient request for referral, delirium, spinal cord compression, brain or leptomeningeal metastases, within 3 months of advanced cancer diagnosis for patients with median survival of $\leq 1$ year, and progressive disease despite second-line therapy [78]. However, some of these criteria may be difficult for oncologists to remember or implement routinely. Palliative care experts have rated a 6-24 month prognosis as appropriate timing [78]; however, this may result in patients receiving care too late, as prognosis tends to be overestimated [79].

Referral criteria are perhaps most useful when used in combination with systematic screening of all oncology outpatients using patient-reported outcome measures such as symptoms or patient-reported functional status [80, 81]. Screening can be completed on paper for in-person visits, or through emailed alerts, text messaging, telephone, and website links.

In Ontario, Canada, patients are screened at every cancer center visit for physical and psychological symptoms [81]. Routine symptom screening improves QoL for patients with advanced cancer when combined with feedback to clinicians in a trial setting [82]. However, in practice, oncologists and oncology nurses may not review the patient-reported outcomes routinely [83].

\section{Automatic referral at diagnosis of advanced cancer}

The major advantage with automatic referral at advanced cancer diagnosis is that it ensures these patients receive palliative care services. Automatic referral for all patients with advanced cancer may help to "normalize" palliative care as part of routine cancer care [84]. A disease-specific approach has been suggested, which identified the point of early integration for 19 different malignancies [85]. While most RCTs of early palliative care have used a model of referring all patients with advanced disease $[2-4 \bullet \bullet, 25 \bullet \bullet, 26,30,32]$, there are practical disadvantages to this model. Not all patients with advanced cancer require symptom management or specialist palliative care at diagnosis $[12,86]$; basic palliative care needs may be met instead by oncologists or primary care providers. In addition, with this model, demands for palliative care will rapidly outstrip scarce resources. Although palliative care is now a recognized medical specialty or subspecialty in most high-income countries and work towards accreditation is underway in several low- and middle-income countries in Asia and Africa $[23,87,88]$, there remains a shortage of specialist palliative care clinicians to meet the needs of all patients with an advanced cancer diagnosis $[89,90]$. In a single-arm feasibility study of early palliative care for patients with advanced lung cancer in India, the feasibility criteria were not met; one challenge was the inability to provide longitudinal care for patients once they were no longer attending hospital clinics [91]. 


\section{Automatic referral based on symptoms or other triggers}

In this model, patients are screened systematically using patient-reported outcomes or other measures, and referral is triggered automatically using predetermined thresholds. The advantage of this system is that it removes gate-keeping that may occur in models requiring oncologist-initiated referral and standardizes who receives palliative care. Composite screening tools with questions about symptoms, functional status, and comorbidities have been validated for initiating a referral [92], but are not in common use. Severity of physical or emotional symptoms may be the best trigger, as addressing symptoms

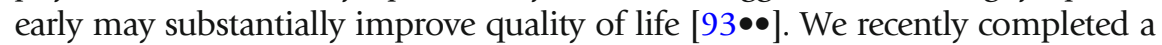
single-arm phase II trial of Symptom screening with Targeted Early Palliative care (STEP) [94]. Patients with advanced cancer were screened routinely for symptoms during their oncology clinic visits; those meeting criteria for symptom severity were referred automatically to the palliative care clinic. This study demonstrated feasibility of a larger phase III trial, which is now in progress.

While automatic referral can improve systematic access to palliative care [95•], support from oncology physicians and nurses is crucial to encourage patients to attend their scheduled appointment [96]. Patients may otherwise decline the triggered referral due to the continued stigma associated with palliative care among patients, their families, and the general public [84]. In our phase II trial of STEP, those who declined the triggered referral had worse symptom control and mood by the 6-month primary endpoint [94]. Renaming the service "supportive care" may be more favorably received by patients, who may otherwise struggle to reconcile the early intervention with the term "palliative care" [84]. Although patient education initiatives may increase acceptability of early palliative care [97], education is also essential for the general public and all health professionals treating patients with cancer in order to fully integrate palliative care with oncology.

\section{Conclusions}

There is now abundant evidence from RCTs in North America and Europe for the benefit of integrating specialized palliative care with oncology early in the course of advanced cancer.

The successful trials have utilized a model of specialized teams providing palliative care in embedded or free-standing clinics. While these RCTs have all been based on routine involvement of palliative care services early in the disease course, this model is resource-intensive and is less feasible in practice, where oncologist-initiated referral still predominates. Models of automatic referral based on symptoms or other triggers are currently being tested in clinical trials. The COVID-19 pandemic has challenged the traditional model of in-person palliative care, and the incorporation of telehealth is rapidly becoming standard practice. The development and provision of palliative care will differ depending on national policy contexts and availability of resources. However, the gold standard for integration of palliative care into oncology will be one that ensures broad access to primary palliative care for all patients while providing timely, targeted, specialized care for those in greatest need. 


\section{Funding}

Dr. Zimmermann is supported by the Rose Chair in Palliative Medicine and Supportive Care, Department of Medicine, University of Toronto.

\section{Declarations}

\section{Conflict of interest}

None of the authors has any potential conflicts of interest to disclose.

\section{References and Recommended Reading}

Papers of particular interest, published recently, have been highlighted as:

- Of importance

- Of major importance

1. World Health Organization. Palliative care. 2020. https:/www.who.int/news-room/fact-sheets/detail/ palliative-care. Accessed November 29, 2020.

2. Zimmermann C, Swami N, Krzyzanowska M, Hannon B, Leighl N, Oza A, et al. Early palliative care for patients with advanced cancer: a cluster-randomised controlled trial. Lancet. 2014;383(9930):1721-30. https://doi.org/10.1016/s0140-6736(13)62416-2.

3. Temel JS, Greer JA, Muzikansky A, Gallagher ER, Admane S, Jackson VA, et al. Early palliative care for patients with metastatic non-small-cell lung cancer. N Engl J Med. 2010;363(8):733-42. https://doi.org/10. 1056/NEJMoa1000678.

4.• Vanbutsele G, Pardon K, Van Belle S, Surmont V, De Laat M, Colman R, et al. Effect of early and systematic integration of palliative care in patients with advanced cancer: a randomised controlled trial. Lancet Oncol. 2018;19(3):394-404. https://doi.org/10.1016/s14702045(18)30060-3

This RCT demonstrated that early palliative care integration improved quality of life of patients with advanced cancer, compared to standard care including psychosocial oncology.

5. Haun MW, Estel S, Rücker G, Friederich HC, Villalobos M, Thomas M, et al. Early palliative care for adults with advanced cancer. Cochrane Database Syst Rev. 2017;6(6):Cd011129. https://doi.org/10.1002/ 14651858.CD011129.pub2.

6.• Kaasa S, Loge JH, Aapro M, Albreht T, Anderson R, Bruera $\mathrm{E}$, et al. Integration of oncology and palliative care: a Lancet oncology commission. Lancet Oncol. 2018;19(11):e588-653. https://doi.org/10.1016/ s1470-2045(18)30415-7

This report proposed the use of systematic symptom assessment and standardized care pathways for early integration of specialized multidisciplinary palliative care into oncology care as a way to combine the tumor-directed approach and the patient-centered approach to achieve the best outcome of patient care.

7.• McDonald J, Swami N, Hannon B, Lo C, Pope A, Oza A, et al. Impact of early palliative care on caregivers of patients with advanced cancer: cluster randomised trial. Ann Oncol. 2017;28(1):163-8. https://doi.org/10. $1093 /$ annonc/mdw438

This cluster-randomised trial demonstrated that caregivers of patients with advanced cancer who received early palliative care experienced improved caregiver satisfaction with care.

8.• Ferrell BR, Temel JS, Temin S, Alesi ER, Balboni TA, Basch EM, et al. Integration of palliative care into standard oncology care: American Society of Clinical Oncology Clinical Practice Guideline Update. J Clin Oncol. 2017;35(1):96-112. https://doi.org/10.1200/ jco.2016.70.1474

This clinical practice guideline represents endorsement by the American Society of Clinical Oncology that advanced cancer patients should receive dedicated interdisciplinary palliative care services early in the disease course, concurrent with active treatment.

9. Jordan K, Aapro M, Kaasa S, Ripamonti CI, Scotté F, Strasser F, et al. European Society for Medical Oncology (ESMO) position paper on supportive and palliative care. Ann Oncol. 2018;29(1):36-43. https://doi.org/ $10.1093 /$ annonc/mdx757.

10. Hui D, Bansal S, Strasser F, Morita T, Caraceni A, Davis $\mathrm{M}$, et al. Indicators of integration of oncology and palliative care programs: an international consensus. Ann Oncol. 2015;26(9):1953-9. https://doi.org/10. 1093/annonc/mdv269.

11. Etkind SN, Bone AE, Lovell N, Cripps RL, Harding R, Higginson IJ, et al. The role and response of palliative care and hospice services in epidemics and pandemics: a rapid review to inform practice during the COVID-19 pandemic. J Pain Symptom Manag. 2020;60(1):e31- 
40. https://doi.org/10.1016/j.jpainsymman.2020.03. 029.

12. Quill TE, Abernethy AP. Generalist plus specialist palliative care-creating a more sustainable model. N Engl J Med. 2013;368(13):1173-5. https://doi.org/10. 1056/NEJMp1215620.

13. Hui D, Hannon BL, Zimmermann C, Bruera E. Improving patient and caregiver outcomes in oncology: Team-based, timely, and targeted palliative care. CA Cancer J Clin. 2018;68(5):356-76. https://doi.org/10. 3322/caac.21490.

14. Hannon B, Swami N, Pope A, Rodin G, Dougherty E, Mak E, et al. The oncology palliative care clinic at the Princess Margaret Cancer Centre: an early intervention model for patients with advanced cancer. Support Care Cancer. 2015;23(4):1073-80. https://doi.org/10. 1007/s00520-014-2460-4.

15. Murray SA, Firth A, Schneider N, Van den Eynden B, Gomez-Batiste X, Brogaard T, et al. Promoting palliative care in the community: production of the primary palliative care toolkit by the European Association of Palliative Care Taskforce in primary palliative care. Palliat Med. 2015;29(2):101-11. https://doi.org/10. 1177/0269216314545006.

16. McCorkle R, Jeon S, Ercolano E, Lazenby M, Reid A, Davies $\mathrm{M}$, et al. An advanced practice nurse coordinated multidisciplinary intervention for patients with latestage cancer: a cluster randomized Trial. J Palliat Med. 2015;18(11):962-9. https://doi.org/10.1089/jpm. 2015.0113

17. Hannon B, Zimmermann C, Knaul FM, Powell RA, Mwangi-Powell FN, Rodin G. Provision of palliative care in low- and middle-income countries: overcoming obstacles for effective treatment delivery. J Clin Oncol. 2016;34(1):62-8. https://doi.org/10.1200/jco.2015. 62.1615 .

18. Groeneveld EI, Cassel JB, Bausewein C, Csikós Á, Krajnik M, Ryan K, et al. Funding models in palliative care: lessons from international experience. Palliat Med. 2017;31(4):296-305. https://doi.org/10.1177/ 0269216316689015 .

19. Schenker Y, Arnold R. Toward palliative care for all patients with advanced cancer. JAMA Oncol. 2017;3(11):1459-60. https://doi.org/10.1001/ jamaoncol.2017.1059.

20. Prabhu Das I, Baker M, Altice C, Castro KM, Brandys B, Mitchell SA. Outcomes of multidisciplinary treatment planning in US cancer care settings. Cancer. 2018;124(18):3656-67. https://doi.org/10.1002/cncr. 31394.

21. Selby P, Popescu R, Lawler M, Butcher H, Costa A. The value and future developments of multidisciplinary team cancer care. Am Soc Clin Oncol Educ Book. 2019;39:332-40. https://doi.org/10.1200/edbk_ 236857.

22. Hoerger M, Wayser GR, Schwing G, Suzuki A, Perry LM. Impact of interdisciplinary outpatient specialty palliative care on survival and quality of life in adults with advanced cancer: a meta-analysis of randomized controlled trials. Ann Behav Med. 2019;53(7):674-85. https://doi.org/10.1093/abm/kay077.

23. Hui D, Bruera E. Integrating palliative care into the trajectory of cancer care. Nat Rev Clin Oncol. 2016;13(3):159-71. https://doi.org/10.1038/ nrclinonc. 2015.201.

24. Hui D, Kim SH, Roquemore J, Dev R, Chisholm G, Bruera E. Impact of timing and setting of palliative care referral on quality of end-of-life care in cancer patients. Cancer. 2014;120(11):1743-9. https://doi.org/10. 1002/cncr.28628.

$25 . \bullet$ Temel JS, Greer JA, El-Jawahri A, Pirl WF, Park ER, Jackson VA, et al. Effects of Early integrated palliative care in patients with lung and gi cancer: a randomized clinical trial. J Clin Oncol. 2017;35(8):834-41. https:// doi.org/10.1200/jco.2016.70.5046

This RCT demonstrated that early integrated palliative care improved QoL for patients with newly diagnosed incurable cancers, and that there were differential effects based on cancer type.

26. Maltoni M, Scarpi E, Dall'Agata M, Zagonel V, Bertè R, Ferrari D, et al. Systematic versus on-demand early palliative care: results from a multicentre, randomised clinical trial. Eur J Cancer. 2016;65:61-8. https://doi. org/10.1016/j.ejca.2016.06.007.

27. Groenvold M, Petersen MA, Damkier A, Neergaard MA, Nielsen JB, Pedersen L, et al. Randomised clinical trial of early specialist palliative care plus standard care versus standard care alone in patients with advanced cancer: the Danish palliative care trial. Palliat Med. 2017;31(9):814-24. https://doi.org/10.1177/ 0269216317705100 .

28. Scarpi E, Dall'Agata M, Zagonel V, Gamucci T, Bertè R, Sansoni E, et al. Systematic vs. on-demand early palliative care in gastric cancer patients: a randomized clinical trial assessing patient and healthcare service outcomes. Support Care Cancer. 2019;27(7):2425-34. https://doi.org/10.1007/s00520-018-4517-2.

29. Franciosi V, Maglietta G, Degli Esposti C, Caruso G, Cavanna L, Bertè R, et al. Early palliative care and quality of life of advanced cancer patients-a multicenter randomized clinical trial. Ann Palliat Med. 2019;8(4):381-9. https://doi.org/10.21037/apm. 2019.02.07.

30. Bakitas M, Lyons KD, Hegel MT, Balan S, Brokaw FC, Seville J, et al. Effects of a palliative care intervention on clinical outcomes in patients with advanced cancer: the Project ENABLE II randomized controlled trial. Jama. 2009;302(7):741-9. https://doi.org/10.1001/jama. 2009.1198.

31. Kim HS, Shin SJ, Kim SC, An S, Rha SY, Ahn JB, et al. Randomized controlled trial of standardized education and telemonitoring for pain in outpatients with advanced solid tumors. Support Care Cancer. 2013;21(6):1751-9. https://doi.org/10.1007/s00520013-1722-x.

32. Bakitas MA, Tosteson TD, Li Z, Lyons KD, Hull JG, Li Z, et al. Early versus delayed initiation of concurrent palliative oncology care: patient outcomes in the ENABLE 
III randomized controlled trial. J Clin Oncol. 2015;33(13):1438-45. https://doi.org/10.1200/jco. 2014.58.6362.

33. Hoek PD, Schers HJ, Bronkhorst EM, Vissers KCP, Hasselaar JGJ. The effect of weekly specialist palliative care teleconsultations in patients with advanced cancer -a randomized clinical trial. BMC Med. 2017;15(1):119. https://doi.org/10.1186/s12916-0170866-9.

34. El-Jawahri A, Greer JA, Pirl WF, Park ER, Jackson VA, Back AL, et al. Effects of early integrated palliative care on caregivers of patients with lung and gastrointestinal cancer: a randomized clinical trial. Oncologist. 2017;22(12):1528-34. https://doi.org/10.1634/ theoncologist.2017-0227.

35. World Health Organization. Telehealth: analysis of third global survey on eHealth based on the reported data by countries 2016. https://www.who.int/gho/goe/ telehealth/en/. Accessed September 17, 2020.

36. Ream E, Hughes AE, Cox A, Skarparis K, Richardson A, Pedersen VH, et al. Telephone interventions for symptom management in adults with cancer. Cochrane Database Syst Rev. 2020;6(6):Cd007568. https://doi.org/ 10.1002/14651858.CD007568.pub2.

37. Fridriksdottir N, Gunnarsdottir S, Zoëga S, Ingadottir B, Hafsteinsdottir EJG. Effects of web-based interventions on cancer patients' symptoms: review of randomized trials. Support Care Cancer. 2018;26(2):337-51. https://doi.org/10.1007/s00520-017-3882-6.

38. Agboola SO, Ju W, Elfiky A, Kvedar JC, Jethwani K. The effect of technology-based interventions on pain, depression, and quality of life in patients with cancer: a systematic review of randomized controlled trials. J Med Internet Res. 2015;17(3):e65. https://doi.org/10. 2196/jmir.4009.

39. Dionne-Odom JN, Azuero A, Lyons KD, Hull JG, Tosteson T, Li Z, et al. Benefits of early versus delayed palliative care to informal family caregivers of patients with advanced cancer: outcomes from the ENABLE III randomized controlled trial. J Clin Oncol. 2015;33(13):1446-52. https://doi.org/10.1200/jco. 2014.58.7824.

40. Kavalieratos D, Corbelli J, Zhang D, Dionne-Odom JN, Ernecoff NC, Hanmer J, et al. Association between palliative care and patient and caregiver outcomes: a systematic review and meta-analysis. Jama. 2016;316(20):2104-14. https://doi.org/10.1001/ jama.2016.16840.

41. Gaertner J, Siemens W, Meerpohl JJ, Antes G, Meffert C, Xander C, et al. Effect of specialist palliative care services on quality of life in adults with advanced incurable illness in hospital, hospice, or community settings: systematic review and meta-analysis. Bmj. 2017;357:j2925. https://doi.org/10.1136/bmj.j2925 This meta-analysis demonstrated that specialist palliative care was associated with improved QoL in patients with advanced illness, and that this effect may be more pronounced in patients who received such care early.
42. Kassianos AP, Ioannou $M$, Koutsantoni $M$,

Charalambous $\mathrm{H}$. The impact of specialized palliative care on cancer patients' health-related quality of life: a systematic review and meta-analysis. Support Care Cancer. 2018;26(1):61-79. https://doi.org/10.1007/ s00520-017-3895-1.

43. Fulton JJ, LeBlanc TW, Cutson TM, Porter Starr KN, Kamal A, Ramos K, et al. Integrated outpatient palliative care for patients with advanced cancer: a systematic review and meta-analysis. Palliat Med. 2019;33(2):123-34. https://doi.org/10.1177/ 0269216318812633.

44. Hausner D, Tricou C, Mathews J, Wadhwa D, Pope A, Swami $\mathrm{N}$ et al. Timing of palliative care referral before and after evidence from trials supporting early palliative care. Oncologist. 2020 (in Press).

This study reported that published evidence demonstrating the benefit of early palliative care for patients with advanced cancer changed referral practices at a comprehensive cancer centre, resulting in earlier referrals to outpatient palliative care.

45. Hui D, De La Rosa A, Chen J, Dibaj S, Delgado Guay M, Heung Y, et al. State of palliative care services at US cancer centers: an updated national survey. Cancer. 2020;126(9):2013-23. https://doi.org/10.1002/cncr. 32738.

46. Mathews J, Zimmermann C. Palliative care services at cancer centres - room for improvement. Nat Rev Clin Oncol. 2020;17(6):339-40. https://doi.org/10.1038/ s41571-020-0374-2.

47. Jordan RI, Allsop MJ, ElMokhallalati Y, Jackson CE, Edwards HL, Chapman EJ, et al. Duration of palliative care before death in international routine practice: a systematic review and meta-analysis. BMC Med. 2020;18(1):368. https://doi.org/10.1186/s12916-02001829-x.

48.• Zimmermann C, Ryan S, Hannon B, Saltman A, Rodin G, Mak E, et al. Team-based outpatient early palliative care: a complex cancer intervention. BMJ Support Palliat Care. 2019. https://doi.org/10.1136/bmjspcare2019-001903

This study described in detail key principles and domains of team-based outpatient early palliative care intervention. Principles are the manner in which care is provided: attentively, flexibly, led by the patient, and centred on the family; domains include coping and support, symptom control, decision-making, and future planning.

49. Hannon B, Swami N, Pope A, Leighl N, Rodin G, Krzyzanowska $M$, et al. Early palliative care and its role in oncology: a qualitative study. Oncologist. 2016;21(11):1387-95. https://doi.org/10.1634/ theoncologist.2016-0176.

$50 . \bullet$ Hannon B, Swami N, Rodin G, Pope A, Zimmermann C. Experiences of patients and caregivers with early palliative care: a qualitative study. Palliat Med. 2017;31(1):72-81. https://doi.org/10.1177/ 0269216316649126

In this qualitative study, patients and their caregivers described benefits of early palliative care, including prompt and personalized symptom management, holistic support for patients 
and caregivers, guidance in decision-making, and preparation for the future.

51. Yoong J, Park ER, Greer JA, Jackson VA, Gallagher ER, Pirl WF, et al. Early palliative care in advanced lung cancer: a qualitative study. JAMA Intern Med. 2013;173(4):283-90. https://doi.org/10.1001/ jamainternmed.2013.1874.

52. Einstein DJ, DeSanto-Madeya S, Gregas M, Lynch J, McDermott DF, Buss MK. Improving end-of-life care: palliative care embedded in an oncology clinic specializing in targeted and immune-based therapies. J Oncol Pract. 2017;13(9):e729-e37. https://doi.org/10. 1200/jop.2016.020396.

53. Walling AM, D'Ambruoso SF, Malin JL, Hurvitz S, Zisser A, Coscarelli A, et al. Effect and efficiency of an embedded palliative care nurse practitioner in an oncology clinic. J Oncol Pract. 2017;13(9):e792-e9. https://doi.org/10.1200/jop.2017.020990.

54. Yennurajalingam S, Prado B, Lu Z, Naqvi S, Williams $\mathrm{JL}$, Lim T, et al. Outcomes of embedded palliative care outpatients initial consults on timing of palliative care access, symptoms, and end-of-life quality care indicators among advanced nonsmall cell lung cancer patients. J Palliat Med. 2018. https://doi.org/10.1089/ jpm.2018.0134.

55. Zimmermann C, Seccareccia D, Clarke A, Warr D, Rodin G. Bringing palliative care to a Canadian cancer center: the palliative care program at Princess Margaret Hospital. Support Care Cancer. 2006;14(10):982-7. https://doi.org/10.1007/ s00520-006-0093-y.

56. Dhollander N, De Vleminck A, Deliens L, Van Belle S, Pardon K. Barriers to the early integration of palliative home care into the disease trajectory of advanced cancer patients: a focus group study with palliative home care teams. Eur J Cancer Care (Engl).

2019;28(4):e13024. https://doi.org/10.1111/ecc. 13024.

57. Malik S, Goldman R, Kevork N, Wentlandt K, Husain A, Merrow N, et al. Engagement of primary care physicians in home palliative care. J Palliat Care. 2017;32(1):3-10. https://doi.org/10.1177/ 0825859717706791 .

58. Sorensen A, Le LW, Swami N, Hannon B, Krzyzanowska MK, Wentlandt K, et al. Readiness for delivering early palliative care: a survey of primary care and specialised physicians. Palliat Med.

2020;34(1):114-25. https://doi.org/10.1177/ 0269216319876915

This survey of Canadian physicians providing palliative care reported that those who had sufficient resources tended to be family physicians, worked in teams, and had access to psychosocial and community resources.

59. Dhollander N, Smets T, De Vleminck A, Van Belle S, Deliens L, Pardon K. Phase 0-1 early palliative home care cancer treatment intervention study. BMJ Support Palliat Care. 2019. https://doi.org/10.1136/bmjspcare2018-001716.
60.• Hannon B, Mak E, Al Awamer A, Banerjee S, Blake C, Kaya $E$ et al. Palliative care provision at a tertiary cancer center during a global pandemic. Support Care Cancer. 2020:1-7. https://doi.org/10.1007/s00520-02005767-5.

This report highlighted the response of the palliative care team at a tertiary cancer center to a global pandemic, which included leveraging technology to convert in-person ambulatory clinic visits to telehealth consults and setting up video conferencing facilities in the inpatient palliative care unit to facilitate communication between patients, their families, and health care teams in the context of restricted hospital visitor policies.

61. Cox A, Lucas G, Marcu A, Piano M, Grosvenor W, Mold $\mathrm{F}$, et al. Cancer survivors' experience with telehealth: a systematic review and thematic synthesis. J Med Internet Res. 2017;19(1):e11. https://doi.org/10.2196/jmir. 6575.

62. Bakitas MA, Mcllvennan CK, Dionne-Odom JN, et al. Rural palliative care. In: Ferrell BR, Ne C, editors. Oxford Textbook of Palliative Nursing. ed 4 ed. Oxford: Oxford University Press; 2014.

63. Krigel S, Nelson E-L, Spaulding A, Krebill H, Leepers M, Doolittle GC. Psycho-oncology via telemedicine: a model to provide services to a rural population. J Clin Oncol. 2014;32(31_suppl):236. https://doi.org/10. 1200/jco.2014.32.31_suppl.236.

64. Piromalli C, Kelley S, Olnes M, DeCourtney C. A09-C Offering 'high-tech, high touch' culturally respectful care: a pilot telepalliative care project in rural Alaska. J Pain Symptom Manag. 2016;52(6):e11. https://doi. org/10.1016/j.jpainsymman.2016.10.014.

65. Paudel BD. HOME palliative care-Nepal: a cell-phone/ website it system. J Clin Oncol. 2019;37(15_suppl):e23134. https://doi.org/10.1200/JCO.2019.37.15_ suppl.e23134.

66. Mandal N. MA07.06 Telephonic communication in palliative care for better management of terminal cancer patients in rural India - an NGO based approach. J Thorac Oncol. 2018;13(10, Supplement):S379-S80. https://doi.org/10.1016/j.jtho.2018.08.371.

67. Mercadante S, Aielli F, Adile C, Bonanno G, Casuccio A. Financial distress and its impact on symptom expression in advanced cancer patients. Support Care Cancer. 2021;29(1):485-90. https://doi.org/10.1007/s00520020-05507-9.

68. Gardiner C, Robinson J, Connolly M, Hulme C, Kang $\mathrm{K}$, Rowland $\mathrm{C}$, et al. Equity and the financial costs of informal caregiving in palliative care: a critical debate. BMC Palliat Care. 2020;19(1):71. https://doi.org/10. 1186/s12904-020-00577-2.

69. Liptrott S, Bee P, Lovell K. Acceptability of telephone support as perceived by patients with cancer: a systematic review. Eur J Cancer Care (Engl). 2018;27(1). https://doi.org/10.1111/ecc.12643.

70. van Gurp J, van Selm M, Vissers K, van Leeuwen E, Hasselaar J. How outpatient palliative care teleconsultation facilitates empathic patientprofessional relationships: a qualitative study. PLoS 
One. 2015;10(4):e0124387. https://doi.org/10.1371/ journal.pone.0124387.

71. Chua IS, Zachariah F, Dale W, Feliciano J, Hanson L, Blackhall L, et al. Early integrated telehealth versus inperson palliative care for patients with advanced lung cancer: a study protocol. J Palliat Med. 2019;22(S1):719. https://doi.org/10.1089/jpm.2019.0210.

72. Dionne-Odom JN, Taylor R, Rocque G, Chambless C, Ramsey T, Azuero A, et al. Adapting an early palliative care intervention to family caregivers of persons with advanced cancer in the rural deep south: a qualitative formative evaluation. J Pain Symptom Manag. 2018;55(6):1519-30. https://doi.org/10.1016/j. jpainsymman.2018.02.009.

73. Wentlandt K, Krzyzanowska MK, Swami N, Rodin GM, Le LW, Zimmermann C. Referral practices of oncologists to specialized palliative care. J Clin Oncol. 2012;30(35):4380-6. https://doi.org/10.1200/jco. 2012.44.0248.

74. Wadhwa D, Popovic G, Pope A, Swami N, Le LW, Zimmermann C. Factors associated with early referral to palliative care in outpatients with advanced cancer. J Palliat Med. 2018;21(9):1322-8. https://doi.org/10. 1089/jpm.2017.0593.

75. Horlait M, Chambaere K, Pardon K, Deliens L, Van Belle $\mathrm{S}$. What are the barriers faced by medical oncologists in initiating discussion of palliative care? A qualitative study in Flanders, Belgium. Support Care Cancer. 2016;24(9):3873-81. https://doi.org/10. 1007/s00520-016-3211-5.

76. Schenker Y, Crowley-Matoka M, Dohan D, Rabow MW, Smith CB, White DB, et al. Oncologist factors that influence referrals to subspecialty palliative care clinics. J Oncol Pract. 2014;10(2):e37-44. https://doi.org/10. 1200/jop.2013.001130.

77. Hui D, Meng YC, Bruera S, Geng Y, Hutchins R, Mori $\mathrm{M}$, et al. Referral criteria for outpatient palliative cancer care: a systematic review. Oncologist. 2016;21(7):895901. https://doi.org/10.1634/theoncologist.20160006 .

78. Hui D, Mori M, Watanabe SM, Caraceni A, Strasser F, Saarto T, et al. Referral criteria for outpatient specialty palliative cancer care: an international consensus. Lancet Oncol. 2016;17(12):e552-e9. https://doi.org/10. 1016/s1470-2045(16)30577-0.

79. Stiel S, Bertram L, Neuhaus S, Nauck F, Ostgathe C, Elsner F, et al. Evaluation and comparison of two prognostic scores and the physicians' estimate of survival in terminally ill patients. Support Care Cancer. 2010;18(1):43-9. https://doi.org/10.1007/s00520009-0628-0.

80. Popovic G, Harhara T, Pope A, Al-Awamer A, Banerjee $\mathrm{S}$, Bryson J, et al. Patient-reported functional status in outpatients with advanced cancer: correlation with physician-reported scores and survival. J Pain Symptom Manag. 2018;55(6):1500-8. https://doi.org/10. 1016/j.jpainsymman.2018.02.015.

81. Li M, Macedo A, Crawford S, Bagha S, Leung YW, Zimmermann $\mathrm{C}$, et al. Easier said than done: keys to successful implementation of the distress assessment and response tool (DART) program. J Oncol Pract. 2016;12(5):e513-26. https://doi.org/10.1200/jop. 2015.010066.

82. Basch E, Deal AM, Kris MG, Scher HI, Hudis CA, Sabbatini P, et al. Symptom monitoring with patientreported outcomes during routine cancer treatment: a randomized controlled trial. J Clin Oncol. 2016;34(6):557-65. https://doi.org/10.1200/jco. 2015.63.0830.

83. Pereira JL, Chasen MR, Molloy S, Amernic H, Brundage $\mathrm{MD}$, Green E, et al. Cancer care professionals' attitudes toward systematic standardized symptom assessment and the edmonton symptom assessment system after large-scale population-based implementation in Ontario, Canada. J Pain Symptom Manag. 2016;51(4):662-72.e8. https://doi.org/10.1016/j. jpainsymman.2015.11.023.

84. Zimmermann C, Swami N, Krzyzanowska M, Leighl N, Rydall A, Rodin G, et al. Perceptions of palliative care among patients with advanced cancer and their caregivers. Cmaj. 2016;188(10):E217-e27. https://doi.org/ 10.1503/cmaj.151171.

85. Gaertner J, Wolf J, Hallek M, Glossmann JP, Voltz R. Standardizing integration of palliative care into comprehensive cancer therapy-a disease specific approach. Support Care Cancer. 2011;19(7):1037-43. https:// doi.org/10.1007/s00520-011-1131-y.

86. Block SD, Billings JA. A need for scalable outpatient palliative care interventions. Lancet. 2014;383(9930):1699-700. https://doi.org/10.1016/ s0140-6736(13)62676-8.

87. Yamaguchi T, Kuriya M, Morita T, Agar M, Choi YS, Goh C, et al. Palliative care development in the AsiaPacific region: an international survey from the Asia Pacific Hospice Palliative Care Network (APHN). BMJ Support Palliat Care. 2017;7(1):23-31. https://doi. org/10.1136/bmjspcare-2013-000588.

88. Goh CR, Lee SY. Education in pain and palliative care in the low- and middle-income countries of the Asia Pacific region. Pain. 2018;159(Suppl 1):S74-s80. https://doi.org/10.1097/j.pain.0000000000001310.

89. Abu-Odah H, Molassiotis A, Liu J. Challenges on the provision of palliative care for patients with cancer in low- and middle-income countries: a systematic review of reviews. BMC Palliat Care. 2020;19(1):55. https:// doi.org/10.1186/s12904-020-00558-5.

90. Kamal AH, Bull JH, Swetz KM, Wolf SP, Shanafelt TD, Myers ER. Future of the palliative care workforce: preview to an impending crisis. Am J Med. 2017;130(2):113-4. https://doi.org/10.1016/j. amjmed.2016.08.046.

91. Deodhar JK, Noronha V, Muckaden MA, Atreya S, Joshi A, Tandon SP, et al. A study to assess the feasibility of introducing early palliative care in ambulatory patients with advanced lung cancer. Indian J Palliat Care. 2017;23(3):261-7. https://doi.org/10.4103/ijpc.Ijpc_ 19_17. 
92. Ostgathe C, Wendt KN, Heckel M, Kurkowski S, Klein C, Krause SW, et al. Identifying the need for specialized palliative care in adult cancer patients - development and validation of a screening procedure based on proxy assessment by physicians and filter questions. BMC Cancer. 2019;19(1):646. https://doi.org/10.1186/ s12885-019-5809-8.

93.• Hoerger M, Greer JA, Jackson VA, Park ER, Pirl WF, ElJawahri A, et al. Defining the elements of early palliative care that are associated with patient-reported outcomes and the delivery of end-of-life care. J Clin Oncol. 2018;36(11):1096-102. https://doi.org/10.1200/jco. 2017.75.6676

This study analyzed data from early palliative care visits for patients with advanced cancer and reported that focus on coping, treatment decisions, and advance care planning was associated with improved patient outcomes.

94. Zimmermann C, Hannon B, Krzyzanowska MK, Li M, Rodin G, Pope A, et al. Phase 2 trial of Symptom screening with Targeted Early Palliative care (STEP) for patients with advanced cancer. J Clin Oncol. 2019;37(15_suppl):11604. https://doi.org/10.1200/ JCO.2019.37.15_suppl.11604.

95. Hui D, Mori M, Meng YC, Watanabe SM, Caraceni A, Strasser F, et al. Automatic referral to standardize palliative care access: an international Delphi survey. Support Care Cancer. 2018;26(1):175-80. https://doi. org/10.1007/s00520-017-3830-5

This survey of international palliative care and oncology experts reported that panelists favored the combination of automatic referral to augment clinician-based referral for early palliative care.

96. Mohammed S, Savage P, Kevork N, Swami N, Rodin G, Zimmermann C. "I'm going to push this door open. You can close it": a qualitative study of the brokering work of oncology clinic nurses in introducing early palliative care. Palliat Med. 2020;34(2):209-18. https://doi.org/10.1177/0269216319883980.

97. Hoerger M, Perry LM, Gramling R, Epstein RM, Duberstein PR. Does educating patients about the early palliative care study increase preferences for outpatient palliative cancer care? Findings from Project EMPOWER. Health Psychol. 2017;36(6):538-48. https://doi. org/10.1037/hea0000489.

\section{Publisher's note}

Springer Nature remains neutral with regard to jurisdictional claims in published maps and institutional affiliations. 